\title{
Innovation Process Model of the Meaning of a Service - A Case Study in Home Automation
}

\author{
Hubert C.Y. Chan \\ ${ }^{1}$ The Hong Kong Polytechnic University, Hong Kong \\ Correspondence: Hubert C.Y. Chan, DBA Graduate, The Hong Kong Polytechnic University, A3, Spring Field \\ Garden, 5-9 Shouson Hill Road West, Hong Kong. E-mail: hubertchan@hkc.net
}

Received: June 24, 2013

Accepted: July 22, 2013

Online Published: September 6, 2013

doi:10.5430/ijba.v4n5p1

URL: http://dx.doi.org/10.5430/ijba.v4n5p1

\begin{abstract}
Instead of a market-pull and technology-push dichotomy, applying one of the Six Senses posited by Pink (2006), the 'Meaning' in product innovation, this study proposes an Service Innovation Process Model based on the Design Driven innovation (DDI) process advocated by Verganti (2009), and business model configuration depicted by Battistella et al., (2012). The latter is already an extension of the former; this study further extends the model to a service design, value co-creation with stakeholders, market penetration, and market feedback as a complete cycle. The objective is to bring in radical service innovation with minimum possible risk. Repertory Grid technique had been employed to explore the affordance of the proposed new applications in the DDI process in a case study of Home Automation. It was found that the findings in the Repertory Grid were quite aligned with those in the DDI process. The case study illustrated stakeholders' involvement throughout the process is required in order to achieve the objective. It also reveals a real life example in designing the detail workflow/process/user experience of a new service after the DDI process. Product-focused had to be complemented with service-focused innovation in order to be sustainable. Although there is no one-size-fits all Innovation process model, this study demonstrates a practical way to explore the 'Meaning' of a Service in a holistic practical approach.
\end{abstract}

Keywords: service innovation process model, meaning of a service, home automation, repertory grid, business model

\section{Introduction}

Businesses are currently in a realm of global competition and the rapid pace of development in technology and communication has made the competition even tenser as product cycles are shortened. Constant innovation is required to keep businesses afloat and grow continuously. Although there are no universal innovation process models that suit all industries, there are still a lot of models have been proven in product-focused innovation. Regret that product-focused innovation to gain competitive advantage worked in the past can no longer provide sustainable competitive advantage due to the ever shortening product life cycle and commoditization of many innovations. However, service-focused innovation which is domain driven and based on tactic knowledge is rather difficult to be imitated and able to sustain for a much longer while (Nonaka and Takeuchi, 1995). Besides, today's sophisticated and well-informed customers seek value beyond price, quality, speed, and customization from products and services. They want the sense of beauty, safety, comfort, affection, or even care as manifested in the total user experience.

Businesses often have to decide what projects or innovations to pursue and what ought to be abandoned. This is part of the innovation process which could either be driven by technological push (by inventing new technology) or customer pull (by addressing customer demands and needs). The former approach believes that customer cannot realize their latent need because they are familiar with the latest technological development which can be applied in new product development. The latter approach believes that customer needs can be expressed through articulated and unarticulated expressions. Articulated needs involve information dealing with what customers say. Data can be collected through traditional methods such as focus groups, personal depth interviews, surveys, questionnaires, and product clinics. Unarticulated needs generally involve information dealing with what customers do and what customers make. Information can be gathered through participant observation, applied ethnography, and contextual enquiry. The context is the everyday situation of use and includes the environment, the people, their goals and processes, and other products (Conley C. V., 2005). Contextual research gives the type of information companies can 
use to develop innovation product ideas which requires an empathetic viewpoint and an ability to suspend an organization's focus on its own products. The process involves gathering rich data from everyday situation, rigorously analyzing it for significant patterns and using these patterns to generate ideas about functions, product lines and strategy.

Understanding customer needs leads to products that are desirable, feasible, and salable (Bayus, B., 2008). However, it has been explained that profitability is usually the ultimate goal of businesses and that successful innovation for the most part equates to profitability. Therefore innovations that proves to be the most marketable leads to success. The problem lies in the element of uncertainty in projecting market response, which introduces the 'risk factor' in the decision making process. Market pull definitely can reduce the risk, but radical change cannot be expected particularly for high-tech product as mentioned before.

In fact, there are many innovation process models which attempt to tackle the problem of 'what to innovate', but it is also recognized that there is no one-size-fits-all model and what is suitable very much depends on a particular industry. The choice of innovation would also vary even within the same industry as it is pointed out by Shlomo Maital and D.V.R. Seshadri (2007) in "Innovation Management" that "Innovation is fundamentally different for entrepreneurial startup companies than it is for established organizations". This is due to the fact that startups need to provide radical innovations to compete over industry veterans while established companies may seek more incremental innovations instead to serve their existing customers. Therefore innovation portfolios would differ among companies even in the same industry as their needs and capabilities in risk taking differ. This argument may not hold anymore in the present short product life cycle era. What is definitely true, however, is that innovation involves risk, the risk of not knowing whether an innovative idea would ultimately succeed.

Businesses must consider risk when considering 'what to innovate'. Implementing unseen new products increases the element of risks and the returns become more unpredictable. Most Companies may feel that the best place to look for growth is outside of, but not too far from, their core business. However, it does not mean that well-established businesses should refrain from implementing 'breakthrough' ideas as they should also continuously expand their customer base and strive to produce new leading products to maintain their market share. Starting businesses, facing the competition of well-established companies, may, on the other hand, consider the creation of a new market a better strategy.

Innovation is not a one-off exercise. It is an on-going process for both entrepreneurial startup and established organization. It seems that an ideal model is one which can make some radical innovations, but minimize the possible risks incurred. Technology push may bring up some radical break through while market pull is less risky. Instead of a market-pull and technology-push dichotomy, Roberto Verganti (2012) promulgated the concept of 'Meaning' of a product explored through a design discourse. It may address the issue of 'what to innovate'. Battistella et al., (2012) further elaborated the concept to business model re-configuration. This may address the issue of business model and strategic alignment. The purpose of this study is to extend the concept to workflow/service/user experience design through value co-creation with stakeholders. This is an important step to assure a service-focused innovation which is more sustainable than product-focused one. A case study applied in Home Automation is followed as a validation.

\section{1 'Meaning' of a Product/Service}

The idea of 'Meaning' has been mentioned in Pink's Six Senses (Pink, 2006). Pink states that in the past 300 years, we have moved from the agricultural age to the conceptual age. Machines will soon replace human physical labor and human left-brains, which is logic, analysis, and sequential aspects of the mind. He advocates six senses that allow humans to succeed in today's conceptual age. Even though the six senses are directed towards striving in the conceptual age, I would like to apply it in service innovation. The table below summarizes how the six senses are used. 
Not just Function but also Design

Not just Argument but also Story

Not just Focus but also Symphony

Not just Logic but also Empathy

Not just Seriousness but also Play

Not just Accumulation but also Meaning
It's not sufficient to create a technological product or a new service only for utilitarian purposes. In today's economically crucial society, products/services must be personally rewarding. The design and appearance of the product is as important as its function. Appearance of the product and the workflow of the service could inflict an emotional or sentimental response from the potential customers.

We live in an information overloaded society. Customers are well aware of the abundance of choices when purchasing a product/service. Technological products with similar functions don't always stand out. Market research must thoroughly investigate to cater towards the customer's lifestyle to successfully derive market segments.

Back in the information age, jobs usually required focus and specialization. However, as white-collar work is replaced by machines, being able to synthesize interdisciplinary skill sets is essential. In innovation, technological products/services should look for holistic and complementary products that can allow customers to link the products to their lifestyle.

Even though logic is a unique human trait, it's not sufficient in the world information overload. Instead, companies need to emphasize with its customers. Innovators should approach product/service development from the customer's perspective.

Laughter benefits health in many cases, so it's important to play in work and life. In innovation, products/service must also be fun and not only for utilization purposes.

We live in a world full of technological goods and services. Technology has eased humans to move past the struggles of survival and allow them to pursue purpose and spiritual fulfillment. In innovation, products/services should not only compete in function, but also create a Meaning to customer.

Most of the contemporary product innovation process usually only address the first five senses but missing the last one. 'Meaning' does not come from user-centered approaches which do not question existing meanings but rather reinforce them. Besides, customers' memory decay rapidly, and even genuine memories are often biased by context (Macdonald et al., 2012). A typical example is the Apple's approach. Its innovation is definitely not user-driven. It does not listen to users, but makes proposals to them (Verganti, 2009). The success of Apple is not only because of it innovative products but also the services through its ecosystem. Verganti (2012) further elaborated the 'Meaning' of a product in his book Design Driven Innovation. He said that people do not buy products merely because of its function but also meaning. 'Meaning' in technological products is something beyond features and functions but evokes a profound emotional, psychological and sociocultural response. It is a strategy that aims at radical changes in a product meanings and languages through a profound understanding of society, culture and technology changes. Firms should therefore look beyond features, functions, and performance and understand the real meaning users give to things.

An example given by Verganti was Wii. Before it was introduced, game consoles offered passive entertainment based on inactive engagement in the virtual world. Whereas other game companies focused on improving the efficiency of controlling the consoles, the Wii was created 'Meaning' by combining exercise and gameplay in active physical entertainment; allowing players real physical experience in using natural movements in playing vigorous games and sports. This illustrates how 'Meaning' attracts customers into using the products. "Meaning has generated products, services, and systems with long lives, significant and sustainable profit margins, and brand value, and they have spurred company growth" (Verganti, 2012). However, soon after that, Microsoft Kinect applied the image processing technology and pushed the video game to another new era. Kinect also open up the API on which 
developers can develop their own applications. Again, this demonstrates that product life cycle of product-focused innovation is very short. It will be replaced or substituted by new technology very soon. Product-focused had to be complemented with service-focused innovation in order to be sustainable. Verganti advocates a Design Driven Innovation Process to explore the 'Meaning' of a product.

\subsection{Design Driven Innovation (DDI)}

Design Driven innovation (DDI) is essentially exploring how the context in which people's lives is evolving. The question is "How could people give meaning to things in this evolving life context?" The same question is being asked by other agents who share the same target customers as we do. They are new technologies suppliers, designers, artists, suppliers of complimentary products, and of course customers. They are the interpreters who are willing to exchange information, test the common assumptions, and discuss the shared visions.

1. Listening- Technology firms can gain knowledge about possible new product meaning by interacting with interpreters, which includes searching outside the current market. These people can lead you step back from the users and take a broader perspectives. This is called Design Discourse.

2. Interpreting- An internal process which the firm assesses the knowledge it gained from 'listening' to interpreters and then integrates this knowledge with its own insights, assets, and technology. With that, the firm then develops its unique proposal. I regard this is a Knowledge Internalization process which includes analysis, reflection, \& synthesis (Xu J. et al., 2010). Internal capability is built up by Internalization while customers and partners involvement enhances the structure of capability.

3. Addressing- Advertising is not the ideal medium when it comes to radical innovation of meanings. It is better leverage the seductive power of the interpreters who not only conduct research, but also influence the context of people's lives.

\subsection{Innovation Process}

There is no one-size-fits-all Innovation model. This study proposes one based on the DDI process and extends it to a novel service as shown in the following diagram (figure 1). To start with the Listening, the Company has to interpret the requirements and make some proposals with its own knowledge/technology or work with outside partners. The new knowledge needs not to be new technology; it can be a new application of existing technology. Radical change thus comes from either new meaning or the new technology provided that it can address the fundamental requirement of that new meaning and interpretation. Knowledge internalization is a process of absorbing and transforming the explicit knowledge into actionable tacit knowledge (Nonaka, 2007). The outcomes not only have to satisfy the requirement but also align with the Company Strategy. The object of strategy is the choice of business model, and the business model employed determines the tactics available to the firm to compete against, or cooperate with, other firms in the marketplace (Casadesus et al., 2010).

I agree that user may not be able to generate new product/service ideas particularly for technological product. However, their subjective interpretation of the new ideas is still useful in exploring a profound emotional, psychological and sociocultural response particularly in service industry. They may have different perception according to their own experience and abilities. If the user interpretation aligns with that of the interpreter, risk of failure would be much smaller logically. The idea of conveying the possibilities for action in one's surroundings is called Affordances (Gibson, 1977). Affordances were defined as the 'action possibilities' latent in the environment. They are measurable and exist independently of whether they are recognized by an organism or actor; but at the same time they exist in relation to the abilities of an actor. This is an attempt to put meaning back into the world, within a relational ontology. In consideration of user's interpretation, it is helpful to site the user in relation to these new applications as there are other affordances that can offer benefits to different users. The theory of affordances points to the conclusion that a socio-technical innovation is likely to involve a great deal more than simply a new product. A new meaning of a product is connected to the purpose of 'why' a product is used but not 'how'. Innovation driven by meaning is connected to a human's new experience of use. It builds on people and their interpretation of why a product or service makes sense in their life, and therefore it is subjective rather than objective (Oberg, 2012). As such, Repertory Grid is an appropriate tool in serving this purpose. The intention is to explore the meaning to user experience and to get the comment on the new proposals. The repertory grid is a technique for identifying the ways that a person construes (interprets/ gives meaning to) his or her experience. Unlike a conventional rating-scale questionnaire, it is not the investigator but the interviewee who provides the constructs on which a topic is rated, and thus provides a way of describing people's construct systems without prejudging the terms of reference. The procedural details will be revealed in the following case study. 
New 'Meaning' may require new business model to convey to its meaning to customer. The 'design discourse' does not address the innovation on the entire business model driven by design. The DDI is a 'sensemaking' process which provides a perception and creation of meaning while the business modeling (a way of doing business) approach is a 'making sense' process that embraces strategy, business model and innovation. Both processes are never-ending iterative and ongoing as the market is dynamic. Since customer experience follows meaning which always refers to the business model perceived in its enacted context, Company should develop not only the way of doing business but also the way they convey meanings, beliefs, values and organization culture. This connection and parallelism between meaning of products and meaning of business model is called the meaning strategy that shapes the business model with the aim to convey a precise meaning as depicted by Battistella et al., (2012). The authors identified three main activities for strategist designer: Activities of sensemaking, Activities of knowledge creation about business model meanings, and Activities of business model reconfiguration. The first activity can be partly covered in the Listening process while second one can be initiated in the Interpreting process. The last one has to convey new meaning through enriching some old building blocks or building some new ones of the business models. The building blocks posited by the authors include the offer, key resource, key activities, revenue flows, cost structure, partner networks, supplier relationship, distribution channel, client segment and relationship.

The next step is the implementation through workflow/ service/user experience design. Design is a communication process to convey three important mechanisms. Firstly, it is a language for explaining the functions of the products and how best to use them. Secondly, it is a language for exciting user through various emotional responses. Thirdly, it is a language for extending second-order meanings. For an example, a luxury watch is not only telling time, but regarded as a kind taste and status in its second-order meaning. Thus, aesthetic innovation is a central organization process to explain the functionality of a new technology and the motivation to set the dominant design as new product technologies emerge (Eisenman, 2012). As posited by Pink in his Six Senses, aesthetic design is important because appearance of the product could inflict an emotional or sentimental response from the potential customers. Another Sense is Empathy. It means the ability to project oneself into a scenario and care for others. In product design scenario, empathy can be achieved through user experience. It is defined as the totality of end users' perception as they interact with a product or service (Kuniavsky, 2010). These perceptions include effectiveness, efficiency, emotional satisfaction, and the quality of the relationship with the entity that created the product or service. The workflow/service/user experience design and portfolio management should be a continuous interactive exercise with the other stakeholders so as to co-create values through the collective creativity of people. The core principle of co-creation is "engaging people to create valuable experiences together" while enhancing network economies (Ramaswamy and Gouillart, 2010). Values refer to important aspects of life from a personal perspective while value chain refers to all the functions and activities an organization needs to undertake in order to create or add value to its products or services from a business perspective (Sanders \& Simons, 2009). It is not a problem identification or solution seeking process; it is a workflow, process, operation, and user experience design process of the new applications generated in the DDI process with the interpreters. Stakeholders are not necessarily all as end-users. For instance, Bio-metric health care measurement devices provided at home involve the caregivers who will come to the home in case of emergency, operators who provided the connection media, and so on. However, users have to be involved as far as operation of the product is concerned. Operation follows design, after constructing the whole context by taking operation as core category, motion semantics is not only helpful for user to comprehend the meaning of products but also useful for designers to appropriately adopt unexpected operations for upholding the level of users' attentions (Cheng, 2010). A deeper meaning or connection with a product will be generated through the interactions that make the human-machine dialogue effortless and rich, providing instant access, enabling the sharing of emotions, and enhancing performance and ability (Henna, 2012). This refers as a collective experience in which users perceived the experience from a different point of view according to their role in the process. Some of them may be the interpreters involved in the Design Discourse process. Instead of considering users as observed subjects they should rather be considered as potential co-creators and experimenters that generate new ideas, play with them, feel, sense and interact within real scenarios and prototyped products/services (Pallot et al., 2010). This is crucial particularly for ubiquitous computing products which are hybrid of hardware, software, services, and user experience. The objective of the experience design is to align developers' understanding of the role a product plays (its meaning) in a person's life with how that person perceives the design of that product. The more successful the user experience of a product/service, the higher the chance that people will adopt it.

During the development process, due to internal or external factors changes, a constant review through Innovation Risk/Portfolio Management is required. It is a dynamic decision process by which new projects are evaluated, selected and prioritized; existing projects may be accelerated, de-prioritized or killed. The portfolio decision process 
encompasses and overlaps a number of decision making processes from technical, marketing, and financial consideration throughout the development process. The idea of portfolio management is to handle risks within acceptable boundaries by making decisions based on analyzed justifications and appropriate allocation of resources. Recognizing that 'appropriateness' differs among companies as what is appropriate depends on their degree of tolerance of risks, a structured tool for risk assessment is what businesses need in order to facilitate decision making. The decision should get the stakeholders involved but not only an internal process. This is especially important when a business has numerous innovation projects at hand to choose from and needs to filter ideas to pursue projects that optimally fit into their innovation portfolio. The most common product portfolio models are financial method (Cooper, R.G. et al., 2006), bubble diagram (Roussel et al., 1991), scoring model (George S. Day, 2007), and strategy method Gourville J.T., 2006).

Ideally, market penetration can ride on the seductive power of the interpreters in the Addressing phase as suggested by Verganti (2009). It is a kind of buy-in in the design phase. Market feedback after the product launch can lead to incremental change, and the lesson learned can further improve the product features. Sometimes new product may come from market requirement with increment change first. After the DDI process, radical change will appear on existing product as well.

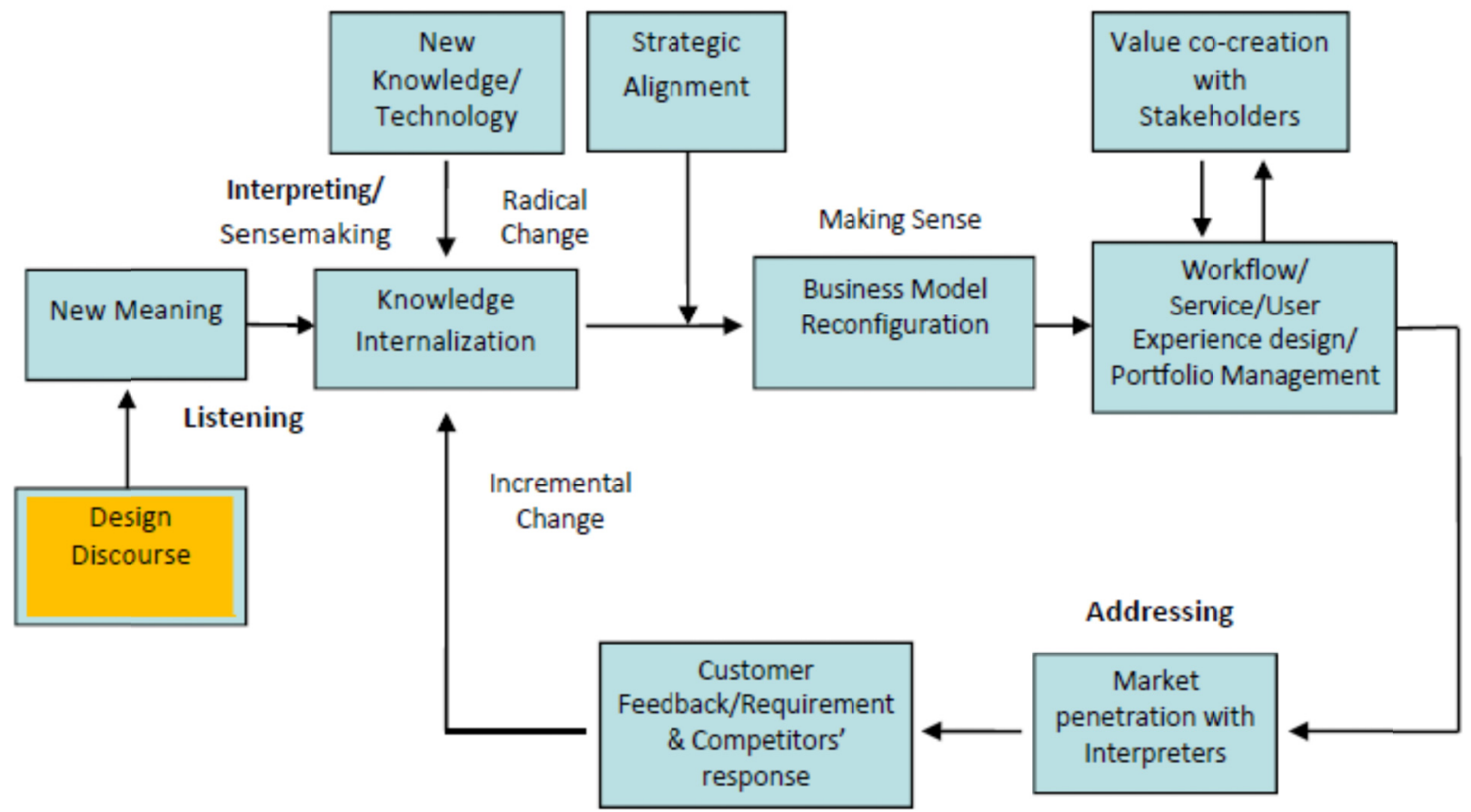

Figure 1. Innovation process model

\section{A Case Study in Home Automation (HA)}

In order to validate the Innovation model, this study worked with a Company which has been designing and implementing Home Automation for seven years in Hong Kong.

HA has been around in mid-Seventies for residential sector mainly for control, home security, mastery, and self-centered lifestyle. With our environmental and health conscious in recent years, the trend is more shifting to energy saving and targeted for use by people with disabilities and for the care of frail older adults - providing safety, security, and ease of self-management, as well as providing both on-site and remote monitoring and healthcare. This mainly because it helps to support disabled people to remain living independently and self-managing in their own homes with their preference and choice; and also provides the assistance to family caregivers and also the possible cost savings derived from driving down the expenses for expensive personal aide assistance and in-person medical care or avoiding costly institutional care.

What's more, once the HA is established in homes, a wide range of services can be offered by other service providers riding on the system. In sum, if accepted by consumers smart homes could ultimately prove to be very 
profitable for a whole range of producers - including builders, telecom equipment suppliers and telecos and cable companies - who could offer smart home services relating to the system while the consumers can get related benefits at the same time. In the past two years, service providers, including telecoms, cable, security, and energy, have all launched additional home automation services for managing energy use or security monitoring to their suites of monthly billed services, The global home automation market is estimated to grow from USD 16, 879.9 million in 2011 to USD 47,378.2 million in 2018 at a compounded annual growth rate of $15.8 \%$ from 2011 to 2018 (http://www.transparencymarketresearch.com/home-automation-market.html). In reality, despite of the proliferation of Internet, mobile device, and affordable broadband services, the adoption still cannot reach the mass market. Many people consider HA is only a luxury product for rich or/and lazy people who just want to control all the appliances with a finger tip or show off their affluent lifestyle. The adoption rate is much slower than anticipated. Besides the cost of ownership, the Diffusion of Innovations model (Rogers, 1962) explained most of the reasons. It states that the rate of adoption is impacted by five factors: relative advantage, compatibility, trialability, observability, and complexity. The first four factors are generally positively correlated with rate of adoption while the last factor, complexity, is generally negatively correlated with rate of adoption. While most of the players believe that these factors will be gone with the affordable broadband, proliferation of mobile devices, and new communication standards.

The slow adoption rate also drew attention of some other scholars. Brush, A. J., et al (2011) conducted home visits to 14 households with home automation in America in order to analyse the hurdle of HA wide deployment. The applications are mainly home security, mastery, self-centered lifestyle with the latest available technologies. The findings illustrate four barriers that need to be addressed. These barriers are high cost of ownership, inflexibility, poor manageability, and difficulty achieving security. Cost of ownership refers to low perceived value. The cost of installing HA can range from a few thousand to millions for a house. A rough estimation for a reasonable package including video door phone, light sensors for curtain, a simple security alarm system, and a few lighting control for a thousand square feet apartment is around US\$5000. Using HA is talking about an experience although it provides some sort of energy saving, the return on investment is difficult to be realized. Inflexibility due to being lock-up by a specific vendor, and structural change at home. The Manageability issue is aroused because HA implementation cannot be finished in one shot, but few more iterations are required, and thus requires a reliable after sales service. It is matter of cost and benefit at the end. Security mainly concerns with remote access which opened up the possibility of being hacked. The authors believed that all these can be overcome through market competition and developing standard eventually, but it doesn't imply that HA adoption will be blooming as those figure released by the marketing research. The question is who is going to benefit and how? Who needs to understand what? Which people and things need to be mobilized to make HA works, and for whom? It seems that some new direction that can induce benefits outweighing the cost of ownership and inflexibility, some added value that can convince developers to plan well ahead and implement in the design phase, and something that worth paying a lifelong after sales service are needed.

This study explored new 'Meaning' in HA through the DDI process. A Design Discourse had been called up with a group of interpreters with the executives of the Company. They are the interior designers who would use HA proposal to their clients, property developers who would provide HA as part of their offers, and telecom service providers who would bundle HA with their broadband services. The question is to define some criteria of Good/Smart living followed by new proposal exploration. After this Listening process, we homogenously envisioned that the criteria of a Good/Smart living in term of quality of life are Care, Convenience, Safety, Social Responsibility, and Community Connection. HA will have its 'Meaning' if it can satisfy these criteria. Since the executives of the Company were well aware of the latest technology available for HA applications and the capacity of the Company, the following proposals were made, and got the endorsement of the interpreters:

- Biometric-data collection at home: Some Biometric-data measurement devices for blood pressure, weight, oxygen level, and heartbeat rate are provided at each unit for data collection to a central server. Any deviation from a normal parameter will alert the caregiver.

- E-notice: Instead of conventional notice broad at the lobby, Management Company can send information to individual resident at an electronic display at home. Information includes maintenance schedule, management account, estate upcoming activities, and promotion.

- NeighborNet: This is an in-house social media platform. Residents can store neighbor's name and location/unit number in different group according to profile. It can broadcast information as a facility booking time or invitation to the respective Group according to the activity nature. 
- Facility booking: Facility booking via Internet to some public recreation utility is getting common. It can be extended to private Estate with some more added-on functions. The booking can inform partners via a social media platform NeighborNet. This feature can also be extended to nearby restaurants, grocery and gift shops with promotional offer so as to build a connecting Community.

\subsection{Repertory Grid}

As mentioned in the proposed Innovation model, user subjective interpretation of the new proposal is essential. As such, I conducted three interview making use of the Repertory Grid. The Grid consists of four parts:

- A topic: our topic is to explore the 'Meaning' of HA.

- A set of elements: The examples of the topic. In our case, they are our new proposals, Biometric-data collection, E-notice, NeighborNet, and Facility booking. I added three more current features. They are Scene setting, Security integration, and Energy saving by sensors. All these will be elaborated in subsequent sections.

- A set of constructs: These are basic terms that the interviews make sense of the elements. There is no pre-defined constructs. All are defined by the interviewee's subjective view.

- A set of ratings of Elements on Constructs. Each element is positioned between the two extremes of the construct using a 5 rating scale system; this is done repeatedly for all the constructs that apply; and thus its meaning to the client is captured. Principle Components Analysis is used to analyze the meaning in our case (Stewart \& Stewart, 1981).

The Grid map was constructed in the following manner:

1. The interview is asked to consider the elements three at a time. The three elements are chosen by the interview or interviewee or by the software program.

2. The interviewee has to identify a way in which two of the elements might be seen as alike, but distinct from, contrasted to, the third. For example, in considering a set of HA features, an interviewee might say that the element 'E-notice' and the element 'Facility booking' are similar because they are both connecting to the Community, whereas the element 'Scene setting' is different because it has nothing to do with the Community. And so we identify one construct that the interviewee uses when thinking about HA: whether they are: 'Connection to the Community as distinct from No connection'. If the other extreme was non-applicable, then I labeled it 'irrelevant'. In this case, the elements 'E-notice' and 'Facility booking' were rated as 1, and the element 'Scene Setting' was rated as 5.

3. The interviewee had to rate all the other elements between these two extremes.

4. The process repeated for another three set of elements until quite a few constructs had been figured out by the interviewee.

5. The rating of each element between each construct would be reviewed and adjusted if required.

6. A Grid map was the produced by Principle Components Analysis.

All the interviewees had experience in using some of those proposed applications but in conventional format. Facility booking was done on computer with web-based platform but not integrated with HA. Biometric-data collection was collected only for personal checkup but not linked with any healthcare program. E-notice and in-house social network are something new. Although I got only three interviews, the results are very consistent except different phrasing for the same thing. For instance, one used 'Protection' for a construct while the other said 'Security'. The implications of the Grid map were discussed with the interviewees for the elicited constructs validation. One of the Grid maps explaining $70 \%$ of the variance is shown below (Figure 2): 


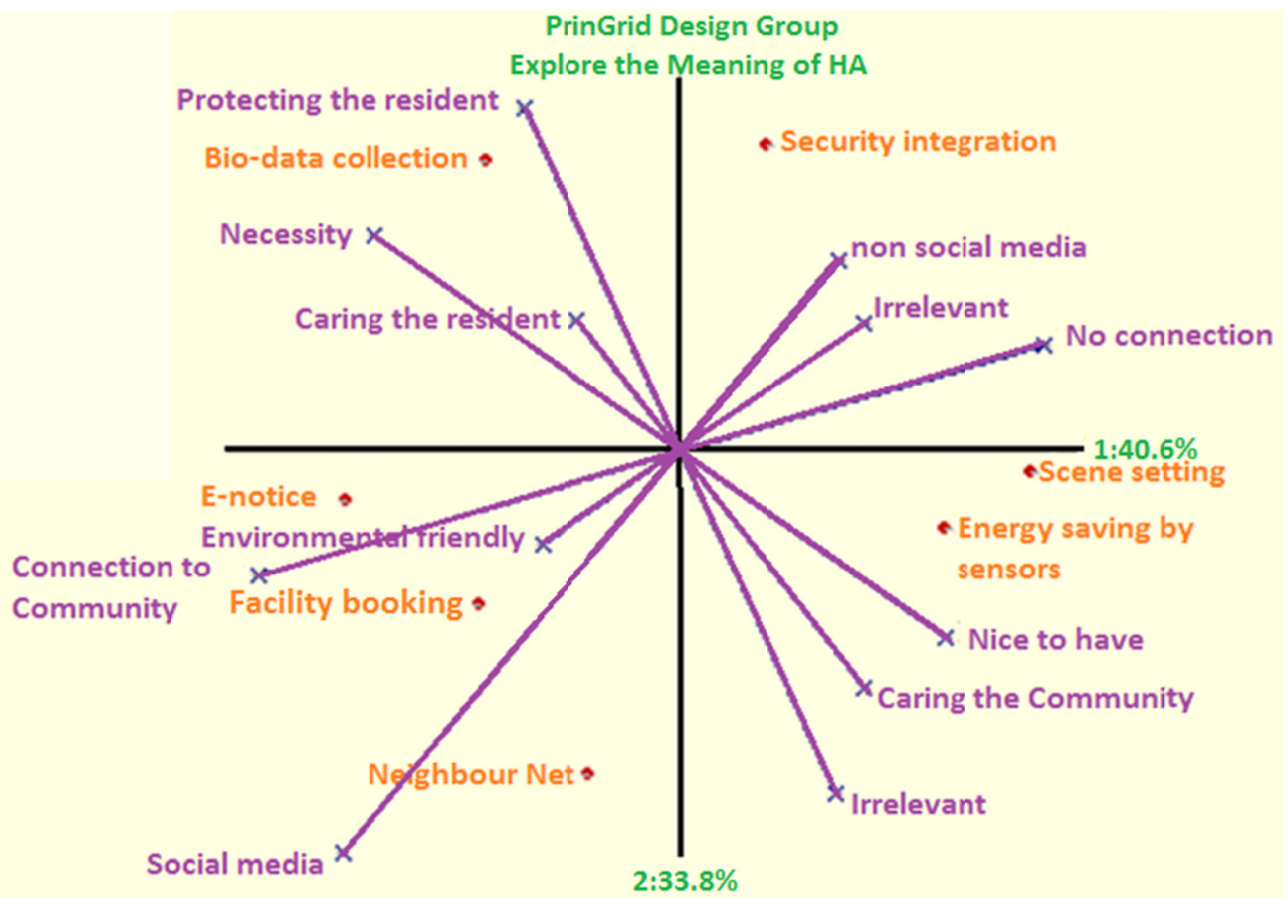

Figure 2. Grip map

Although the sample size is small, the findings is aligned with the interpreters' viewpoint, we can draw some agreeable observations on the Grid map, Biometric-data is considered as a necessity and protection to the resident. E-notice and Facility booking are regarded as environmental friendly and create connection to the Community. NeighborNet is a social media platform with connection to the community. Scene setting and Energy saving are nice to have features for caring the community. Security integration is a protection to the resident feature. With this analysis, we found that the current features except the Security integration, Scene setting and Energy saving were in fact cannot fully satisfy the criteria of Good/Smart living in quality of life. Recalling the concept of affordance which brings together physical properties, agency, and meaning, these features does not cause behavior, but can constrain and enable it (Costall, 1995). They are the enablers of a safe, caring, and community connection living environment. With that we have addressed the 'how' in providing specific HA features to meet the criteria of Good living. The findings are also supported by the Maslow's five level human psychological needs: physiological, safety, love/belonging, esteem, and self-actualization. Deci and Ryan (2000) further elaborated in the self-determination theory that psychological needs include autonomy: the ability to determine own behavior without external influence (Bio-metric data self-collection), competence: to experience oneself as capable and competent in controlling the environment and being able to reliably predict outcomes (facility booking), and relatedness: to care for and be related to others (Neighbornet).

New business model was also explored in the Design Discourse. It was suggested that equipment cost could be paid back in the monthly Estate management fee. It is better than one -off investment either paid by the resident or the property developer so as to lower the entry barrier. Another suggestion is to generate advertising or commission income from the nearby shops in posting their promotion to each unit of the Estate. This is a triple win business model for the residents who can enjoy the benefits and convenience offered by the shops, the platform provider, and the caregivers. Apparently, the business model reconfiguration had been started in the Design Discourse phase. There is not a clear demarcation between the Listening, Interpreting, and business model configuration in the actual practice of this case study. Sensemaking and making sense may happen at the same time provided that they are aligned with the Company overall strategy.

\subsection{Value Co-creation with Stakeholders}

The next step was the workflow/user experience design stage. Stakeholders who are the caregivers, service providers, property Management Company were all involved. Several iterations were required to go through the cosmetic 
design, prototype approval, and functional testing. It was found that 'Meaning' exploration had been extended beyond the DDI and making sense process. More meanings had been created in the value co-creation process with the stakeholders. This case study was a design-and-build project between a Home Automation specialist and a property developer for a luxury elderly project. The workflow/user experience design had to be aligned with the theme of home feel holistic care services. As an illustration, the detail specifications of the Biometric data collection service were issued in the value co-creation process.

\subsubsection{Biometric -Data Collection}

Biometric-data collection for blood pressure, heart beat rate, blood glucose and oxygen level, and its analysis are required in a home care system at daily basic as one of the 'Meanings' explored in the DDI process. It is categorized as an Autonomy enhancement by Coelho V, (2012). Home-based technologies allow elderly to adapt to changing physical and cognitive function and preserve living in a familiar environment within an established social network. Home care is different from hospital treatments. Home care is more focused on long term well-being and on calling upon specialized treatment. It should help people live independently and focus on quality of life. The role of these technologies is to empower elderly to self-manage an independent living and to minimize adverse effects on their caregiver's stress. A similar approach is used for Community Hospitals but with a great emphasis on long-term engagement:

- Respect and involve people who use services.

- Consent to care and treatment.

- Care for the welfare of people who use services.

- Meet nutritional needs.

- Cooperate with other providers.

- Safeguard people who use services from abuse.

- Cleanliness and infection control.

- Management of medicines.

- Safety and suitability of premises.

- Safety, availability and suitability of equipment.

- Requirements relating to workers.

- $\quad$ Staffing.

- Supporting workers.

- Assessing and monitoring the quality of service provision.

- Complaints.

- Records.

This system benefits both patients and doctors.

For Patients

- A reliable reminder of routine check-ups.

- Attention to the patient.

- Saves time by eliminating the need to travel to clinics.

- Lower costs due to fewer visits.

- No more queues and waiting time.

- Real-time communication.

- Eases worry of sudden changes or symptom of illness.

For Doctors

- Achieves time efficiency. Consequently, they can see more patients.

- Lessens the consultation time.

- Instantly provides attention and care to those in need. 
Here is a diagram to illustrate the biometric-data collection system; data collection can be done at the resident unit by the resident himself/herself for Home Care while more sophisticated measurements are provided at the Day Care Center:

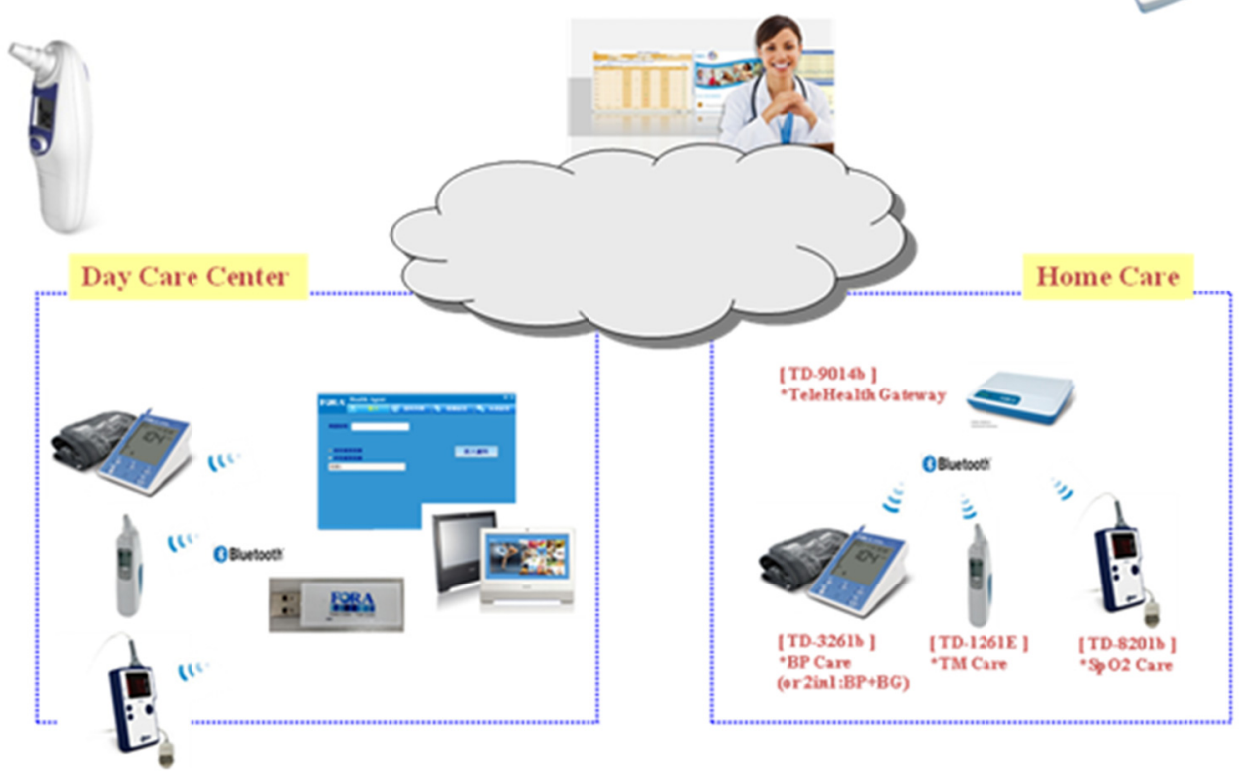

Biometric-data collection system

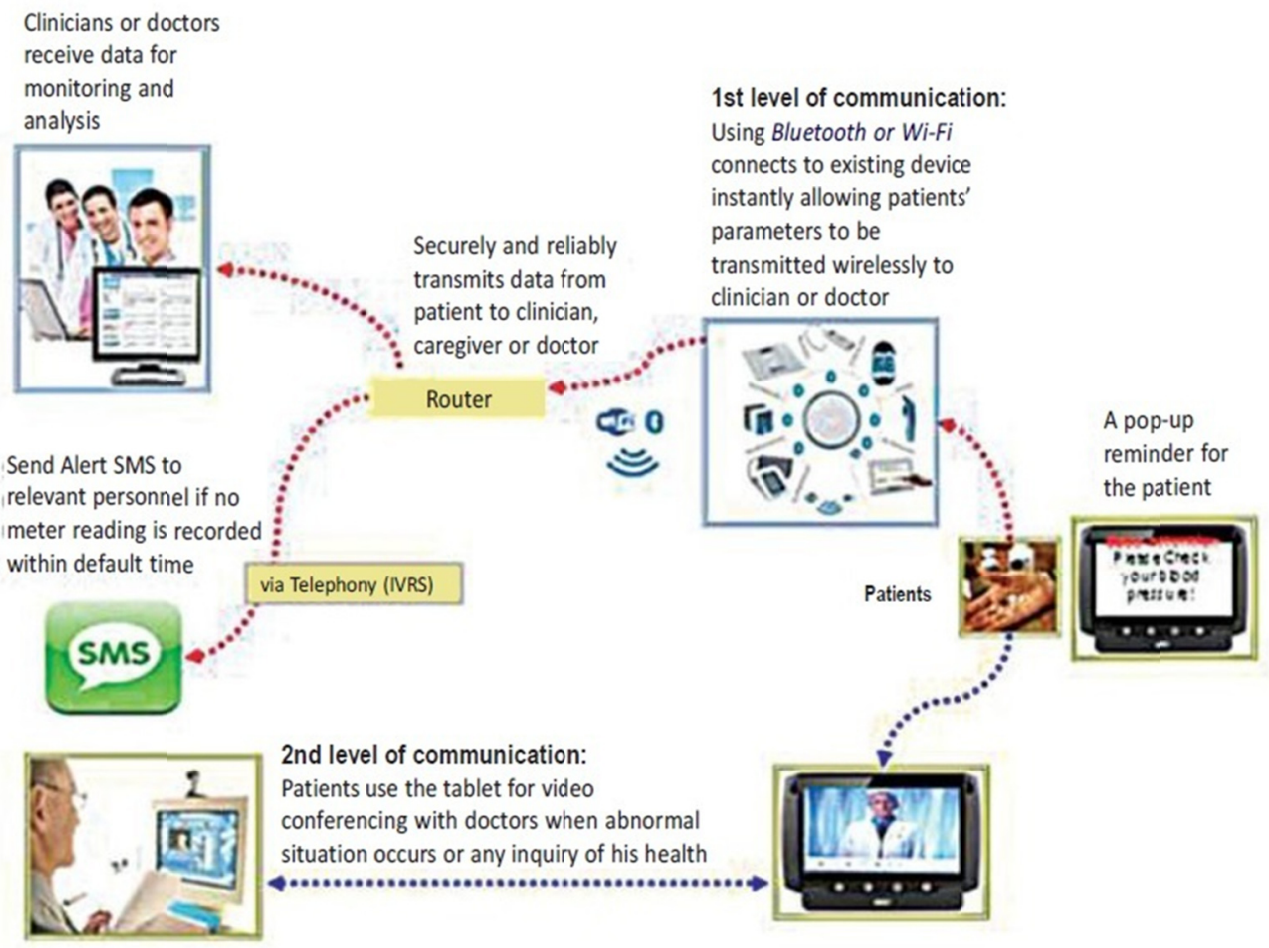

System overview 
The system runs on a web-based platform. It allows caregivers to remotely monitor the patient's vital parameters via the Internet. The collected data can be incorporated into the private or public central electronic records for analysis. Patients, family and healthcare managers can then easily gather and analyze the health records remotely and therefore respond efficiently to a patient's situation. There is a built-in patient search function, full medical History /Notes for the patient, Abnormal Data Warning, Strip Usage Control, and Data Export capability. Telemedicine can be conducted right the way if the parameters exceed a normal level with the following advantges:

- Provide flexibility and scalability to health professionals.

- Improve medical service quality and accessibility for healthcare consumers.

- No geographic restriction.

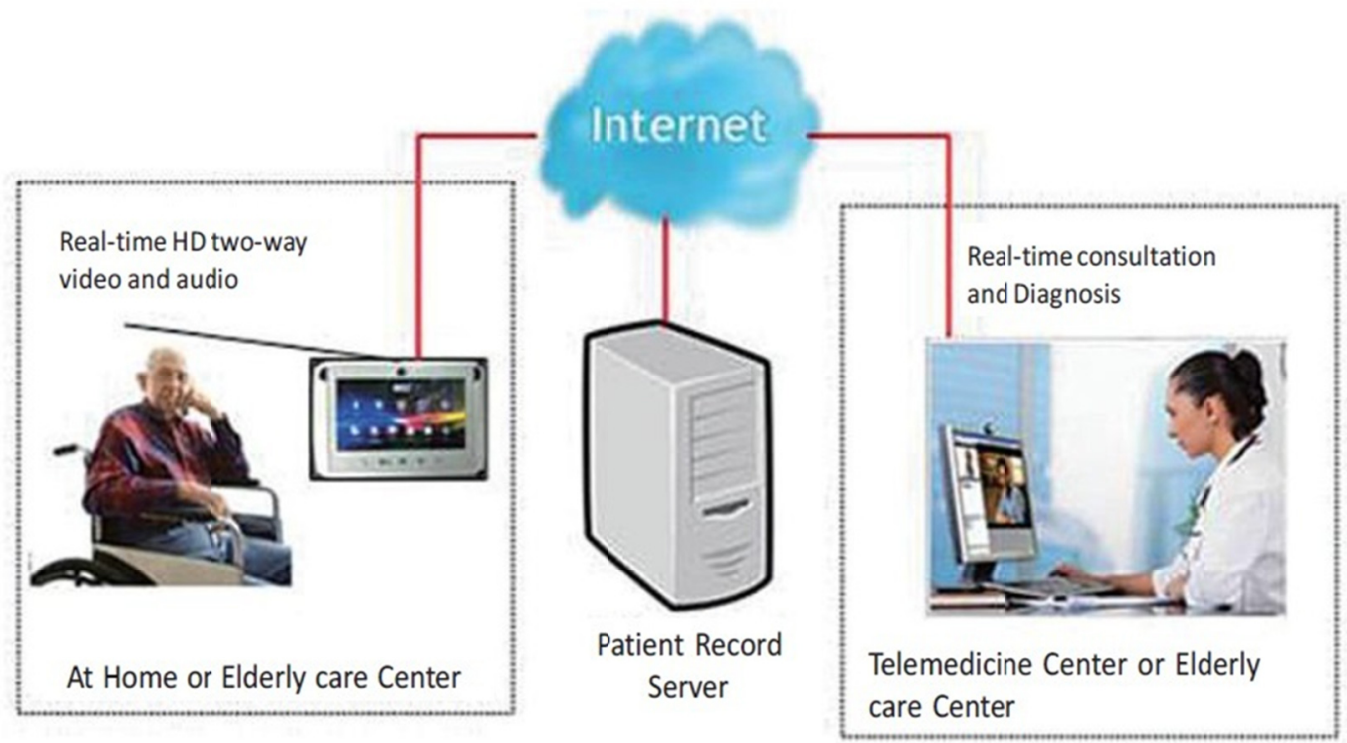

Telemedicine system

\section{Discussion}

This case study followed the framework of the proposed model. The innovations had been generated in the DDI process and validated by the Repertory Grid. The project involves some new hardware development but the core part is the workflow/service/software development. It is a kind of Service Science which is defined as an integration of various disciplines such as management, engineering, accounting, finance and operations, with the aim of preparing the next wave of innovators in contributing to a service economy ( $\mathrm{Ng}$ et al., 2009). It includes close supplier relationship, customer interaction, creation and exchange of codified and tacit knowledge, simultaneity of production and consumption, combining knowledge into useful systems, exchange focused on processes and experience, and finally, exploitation of ICT and transparency (Chesbrough and Spohrer, 2006). Thus, interdisciplinary and cross-disciplinary approaches are required to understand how services should be designed, delivered and supported. Service innovation is less relies on in-house R\&D, but more on collaborative network. A value network contains all stakeholders, integrates their various resources and ultimately propels customers into a co-creation role, thereby transforming them from "passive audiences" to "active players" (Prahalad and Ramaswamy, 2000). Service innovation can be pulled by the customer (client-driven), pushed by a service provider (service provider-driven) or balanced (strategic congruence) as posited by Moller et al. (2008). The co-created value was the workflow and the user experience which were designed according to the feature specifications. The operation procedures will then be reviewed together with some potential users so as to enable the sharing of emotions, and enhance performance and ability of the products. This is the vital part of the whole project since the product-focused hardware can be substituted or replaced in a few years time due to advance in technology while the service-focused software part is unique and domain driven. Some workflow may be modified according to the new technology available in the future, but the core services will remain. The project scope covered the network design, communication devices, video door phone, anti-wandering system, security access control and so on. Thus, items prioritization had been addressed in the portfolio management with the stakeholders throughout the course. 


\section{Limitations}

This case study covered the exploration of new 'Meaning' and the business model configuration to a certain extent in the Design Discourse. Repertory Grid is a good tool to explore the affordance of the new proposals. As such, the sample of interviews could be increased to improve the findings accuracy. The project was in the process of workflow/user experience design/portfolio management stage by the time this paper was finished. It may take at least one more year to reach the Addressing stage after which customer feedback will be collected, and incremental change may be needed accordingly. The interpreters' buy-in process already assured their participation in the future. A longitudinal study is thus required to follow through the case. Multi- cases study is preferable for further modification of the proposed model.

\section{Conclusion}

An Innovation process model based on the Design Driven innovation (DDI) process advocated by Verganti (2009), and business model configuration depicted by Battistella et al., (2012) had been extended in exploring a 'Meaning' of a Service. The model had been validated in a case study of Home Automation applications. It was found that the findings in the Design Discourse by the interpreters were aligned with the end user interpretation found in the Repertory Grid. The findings of new applications or radical changes, and business model reconfiguration are not comprehensive enough in service-focused innovation. The detail workflow/service/user experience design, and portfolio management have to be co-created with stakeholders. The process of Listening, Interpreting, sensemaking, making sense, and value co-creation does not necessarily progress in a linear fashion - the activities may occur in parallel and in diverse order. This is a new approach which can extend the market-pull and technology-push dichotomy, and may bring in a radical change with minimum risk in service-focused innovation. Stakeholders' involvement in the whole process is required in order to achieve this objective.

\section{References}

Battistella, Cinzia, Gianluca Biotto, \& Alberto F. De Toni. (2012). From design driven innovation to meaning strategy. Management Decision, 50(4), 718-743. http://dx.doi.org/10.1108/00251741211220390

Bayus, Barry L. (2008). Understanding Customer Needs. Handbook of Technology and Innovation Management, Edited by Scott Shame, Chp. 3, pp.115-141.

Brush, A. J., Lee, Bongshin, Mahajan, Ratul, Agarwal, Sharad, Saroiu, Stefan, \& Dixon, Colin. (2011). Home automation in the wild challenges and opportunities. Proceedings of the 2011 annual conference on Human factors in computing systems. ACM. http://dx.doi.org/10.1145/1978942.1979249

Casadesus-Masanell, Ramon, \& Joan Enric Ricart. (2010). From strategy to business models and onto tactics. Long Range Planning, 43(2), 195-215. http://dx.doi.org/10.1016/j.lrp.2010.01.004

Cheng, SW. (2010). Operation Follows Meanings--以雙重隱喻之燈具探索語意式操作脈絡. 設計學報, 15(3), 001.

Chesbrough, H., \& Spohrer, J. (2006). A research manifesto for service science. Communications of the ACM, 49(7), 35-40. http://dx.doi.org/10.1145/1139922.1139945

Coelho, Vivien. (2012). Creating Ambient Intelligence: Applications and Design Guidelines for the Home.

Conley, Chris V. (2005). Contextual Research For New Product Development. The PDMA Handbook of New Product Development, Second Edition, Edited by Kenneth B. Kahn, Chp. 15, pp.228-248.

Cooper, Robert G., Edgett, Scott J., \& Kleinschmidt, Elko J. (2006-2007). Portfolio Management for New Product Development: Results of an Industry Practices Study. Product Development Institute Inc.

Costall, A. (1995). Socializing affordances. Theory and Psychology, 5(4), 467-481. http://dx.doi.org/10.1177/0959354395054001

Deci, E.L., \& Ryan, R.M. (2000). The "what" and "why" of goal pursuits: human needs and the self-determination of behavior. Psychological Inquiry, 11(4), 227-268. http://dx.doi.org/10.1207/S15327965PLI1104_01

Eisenman, Micki. (2012). Understanding Aesthetic Innovation in the Context of Technological Evolution. Academy of Management Review.

Ellen Kathrine Hansen. (2010, August). Home, Smart Home. IEEE Spectrum, 47(8), 34-38. http://dx.doi.org/10.1109/MSPEC.2010.5520626 
George S. Day. (2007). Is it real? Can we win? Is it worth doing?: Managing risk and reward in an innovation portfolio. Harvard Business Review, 12.

Gibson, J.J. (1977). The theory of affordances. In R. Shaw and J. Bransford (Eds.), Perceiving, Acting, and Knowing. Lawrence Erlbaum Associates, Hillsdale, NJ.

Gourville John T. (2006, June). Eager Sellers and Stony Buyers: Understanding the Psychology of New-Product Adoption. Harvard Business Review.

Hanna, Parrish. (2012). The Evolution of Simplicity and Meaning. Journal of Product Innovation Management, 29(3), 352-354. http://dx.doi.org/10.1111/j.1540-5885.2012.00906.x

Kuniavsky Mike. (2010). Smart Ting: Ubiquitous Computer User Experience Design. Elsevier, Inc..

Macdonald, Emma K., Wilson, Hugh N., \& Konus, Umut. (2012, Sept.). Customer Insight-In Real Time. Harvard Business Review, N.p., Web. 1 Sept. 2012. Retrieved from http://hbr.org/2012/09/better-customer-insight-in-real-time/ar/1

Maital, S., \& Seshadri, D. V. R. (2007). Innovation management: Strategies, concepts and tools for growth and profit. Response Books.

Maslow, A. (1943). A theory of human motivation. Psychological Review, 50, 370-396. http://dx.doi.org/10.1037/h0054346

Moller, K., Rajala, R., \& Westerlund, M. (2008). Service innovation myopia? A new recipe for client provider value creation. California Management Review, 50(3), 31-48. http://dx.doi.org/10.2307/41166444

Ng, I., Maull, R., \& Yip, N. (2009). Outcome-based contracts as a driver for systems thinking and service-dominant logic in service science: evidence from the defence industry. European Management Journal, 27, 377-387. http://dx.doi.org/10.1016/j.emj.2009.05.002

Nonaka, Ikujiro. (2007). The Knowledge-Creating Company. Harvard Business Review.

Nonaka, I., \& Takeuchi, H. (1995). The Knowledge Creating Company. Oxford University Press. New York, NY.

Norman, Donald. (1998). The invisible Computer: Why good products can fail, the personal computer is so complex, and information appliances are the solution. Cambridge: The MIT Press.

Öberg, Åsa. (2012). Innovation driven by meaning. Diss. Mälardalen University.

Pallot, M., Trousse, B., Senach, B., \& Scapin, D. (2010). Living Lab Research Landscape: From User CentredDesign and User Experience towards User Cocreation. Proceedings of the Living Lab Summer School, Paris, August 2010.

Pink, Daniel H. (2006). A Whole New Mind: Why Right-brainers Will Rule the Future. New York: Riverhead.

Prahalad, C.K., \& Ramaswamy, V. (2000). Co-opting customer competence. Harvard Business Review, 78, 79-90.

Ramaswamy, V., \& Gouillart, F. (2010). The Power of Co-creation. The Free Press, New York, NY.

Rogers, Everett M. (1962). Diffusion of Innovations. The Free Press. New York.

Roussel, P.A., Saad, K. N., \& Erickson, T. J. (1991). Third Generation R \& D. Managing the Link to Corporate Strategy. Arthur D. Little.

Sanders, L., \& Simons, G. (2009). A Social Vision for Value Co-creation in Design. Open Source Business Resource. Retrieved January 2012, from http://www.osbr.ca/ojs/index.php/osbr/article/view/1012/973

Stewart \& Stewart. (1981). Business applications of repertory grid. McGraw Hill, UK, pp. 46-66.

Takayama, L., Pantofaru, C., Robson, D., Soto, B., Barry, M., \& Forward, P. (2012). Making Technology Homey: Finding Sources of Satisfaction and Meaning in Home Automation.

Verganti, Roberto. (2009). Design Driven Innovation: Changing the Rules of Competition by Radically Innovating What Things Mean. Harvard Business Press: Boston.

Verganti, Roberto. (2012). Changing the Rules of Competition by Radically Innovating What Things Mean. Design-Driven Innovation, Web. 5 Apr. 2012. Retrieved from http://www.designdriveninnovation.com/

$\mathrm{Xu}$, J., Houssin, R., Caillaud, E., \& Gardoni, M. (2010). Macro process of knowledge management for continuous innovation. Journal of Knowledge Management, 14(4), 571-591. http://dx.doi.org/10.1108/13673271011059536 